\title{
Heritability of Type II (non-insulin-dependent) diabetes mellitus and abnormal glucose tolerance - a population-based twin study
}

\author{
P.Poulsen ${ }^{1}$, K. Ohm Kyvik ${ }^{2}$, A. Vaag ${ }^{1,3}$, H. Beck-Nielsen ${ }^{1}$ \\ ${ }^{1}$ Odense University Hospital, Department of Endocrinology and Internal Medicine, Odense, Denmark \\ ${ }^{2}$ Genetic Epidemiology Research Unit, Odense University, Odense, Denmark \\ ${ }^{3}$ Hvidovre Hospital, Dept. of Endocrinology, Hvidovre, Denmark
}

\begin{abstract}
Summary To elucidate the relative importance of genetic and environmental factors on the development of Type II (non-insulin dependent) diabetes mellitus, we examined a sample of twins $(n=606)$ ascertained from the population-based Danish Twin Register. Based on a standard $75 \mathrm{~g}$ oral glucose tolerance test and current WHO criteria we identified 62 pairs in which one or both had Type II diabetes. The probandwise concordance (monozygotic: 0.50; dizygotic: 0.37 ) for Type II diabetes per se was not very different. When including the twins with impaired glucose tolerance (IGT), however, the probandwise concordance for abnormal glucose tolerance was significantly different between monozygotic (0.63) and dizygotic $(0.43)$ twin pairs, $(p<0.01)$. These findings were supported by the heritability estimates for Type II diabetes per se $(26 \%)$ and for abnormal glucose tolerance $(61 \%)$. The metabolic variables, insulin resistance and insulin secretion, and anthropometric vari-
\end{abstract}

ables, body mass index and waist to hip ratio, known to be associated with the development of glucose intolerance had a heritability of $26,50,80$ and $6 \%$ respectively. This study confirms the notion of a multifactorial aetiology of Type II diabetes. It supports the contribution of non-genetic aetiological components in the development of Type II diabetes per se. The study also indicates a role for genes in the aetiology of abnormal glucose tolerance. We therefore propose that genetic predisposition is important for the development of abnormal glucose tolerance. Non-genetic factors, however, might play a predominant role in controlling whether a genetically predisposed individual progresses to overt Type II diabetes. [Diabetologia (1999) 42: 139-145]

Keywords Twins, Type-II (non-insulin-dependent) diabetes mellitus, abnormal glucose tolerance, concordance rates, heritability.
Type II (non-insulin-dependent) diabetes mellitus is a heterogeneous and complex disease presumably with a multifactorial aetiology comprising genetic and environmental factors [1]. A strong genetic influence has been suggested due to a greater concordance for Type II diabetes found in monozygotic

Received: 24 April 1998 and in final revised form: 18 September 1998

Corresponding author: Prof. H. Beck-Nielsen, Odense University Hospital, Dept. of Endocrinology, Sdr. Boulevard, DK5000 Odense C, Denmark

Abbreviations: MZ, Monozygotic; DZ, dizygotic; IGT, impaired glucose tolerance; OGTT, oral glucose tolerance test; $\mathrm{A}$, additive genetic variance; $\mathrm{C}$, shared environmental variance; $\mathrm{E}$, non-shared environmental variance.
(MZ) twin pairs, often referred to as more than $90 \%$, compared with dizygotic (DZ) twin pairs [2-9]. Most previous twin studies, however, have ascertained twin pairs through sampling from diabetic outpatient clinics or advertising, with the potential of ascertainment bias due to disproportionate sampling of concordant and MZ pairs [2, 4-6, 8]. Furthermore clinic-based studies tend to include more severe cases of diabetes. Consequently, the reported concordance rates might have been overestimated due to selection bias especially for the MZ pairs. When employing record linkage to identify diabetic twins, as it was done in a Finnish study [9], asymptomatic or diet-treated diabetic patients or both who have not been hospitalised are not included. This may lead to an underestimation of the number of diabetic sub- 
jects and therefore potentially to biased concordance rates. Using population-based twin registries, such as The Danish Twin Register, allows ascertainment of twins independent of disease status [10]. Concordance rates may still be erroneous, however, if the diagnosis of Type II diabetes relies only on self-reported information. Thus, asymptomatic undiagnosed diabetic patients are not included. Moreover, concordance rates might be overestimated because a cotwin of a diabetic twin possibly is more likely to have been screened for asymptomatic diabetes. This can be avoided by clinical examination and diagnostic testing of all participating twins (diabetic and nondiabetic subjects) which permits identification of all patients with Type II diabetes, symptomatic as well as asymptomatic, and identification of subjects with impaired glucose tolerance (IGT) and therefore at risk of developing Type II diabetes later on. Only in the American population-based study [7] were all subjects clinically examined. A standardised diagnostic test, however, was not used in that study.

In this cross-sectional study we report prevalences, concordance rates and recurrence risks of Type II diabetes and abnormal glucose tolerance [Type II diabetes mellitus or impaired glucose tolerance (IGT) or both] for MZ and DZ twins ascertained from the population-based Danish Twin Register. We estimate the heritability for Type II diabetes, abnormal glucose tolerance, metabolic and anthropometric variables associated with the development of glucose intolerance (i.e. plasma glucose and insulin, weight, BMI and waist-to-hip ratio) by means of interclass correlations and biometric model fitting analyses.

\section{Subjects and methods}

Subjects. Subjects were identified through The Danish Twin Register [11, 12]. We sent a mailed questionnaire in November 1994 to same sex MZ and DZ twin pairs, both thought to be alive according to civil registry records. A total of $3074 \mathrm{MZ}$ and DZ twins (i.e. 1537 pairs) born in Funen county, Denmark, between 1931 and 1940 (age 55 to 64 years) or born in other areas of Denmark between 1921 and 1930 (age 65 to 74 years) were included. The study was approved by the regional ethics committees and the study was conducted according to the principles of the Helsinki Declaration.

Twins were asked about physical similarity and mistaken identity in order to establish zygosity, i. e. the similarity method was used $[11,13]$. This method has been evaluated by comparison with serological zygosity testing, revealing a misclassification rate of under $5 \%$ [11]. Twins were asked whether they had diabetes, and if so, information on age at onset and use of insulin and duration of use were requested. Subjects diagnosed at 40 years or older who did not receive insulin treatment within 1 year of onset were classified as having Type II diabetes. The prevalence of Type II diabetes at 40 years or younger has previously been shown to be small $(0.03 \%)$ [14]. Each twin was asked whether he or she was willing to participate in a study of diabetes involving a standard oral glucose tolerance test (OGTT) and height, weight and other anthropometric measurements.
A total of $2273(73.9 \%)$ individual twins answered the questionnaire. Both members of 975 twin pairs $(63.4 \%$ of total twin population) responded to the questionnaire. One or both members of 451 pairs declined to participate while both members of 129 pairs did not answer at all; these 580 pairs were not contacted. The remaining 395 pairs $(25.7 \%)$, comprised twin pairs in which either both members indicated a willingness to participate in a clinical study (239 pairs), or one twin was willing while the other did not answer (156 pairs). These subjects were potentially available for our study and we contacted them. The final sample of twins clinically examined was 303 pairs $(19.7 \%)$.

Methods. Subjects underwent a standardised $75 \mathrm{~g}$ OGTT after a 10-12 h overnight fast. Peripheral venous blood was taken before oral glucose ingestion and 30 and 120 minutes later. Plasma glucose concentrations were analysed by the glucose dehydrogenase oxidation method. Plasma insulin concentrations were measured using a two-site, two-step, time resolved immunofluorometric assay (DELFIA, Turku, Finland) as described previously [15]. Cross reactivities with proinsulin, Cpeptide and Des(31,32)-split product in the insulin assay were all less than $0.4 \%$. Intraassay coefficients of variation in the physiological ranges were $3.6-4.3 \%$ for plasma insulin. Interassay coefficients of variation were $1.7-3.4 \%$ for plasma insulin.

Weight and height were measured with the subject in lightweight clothes with the shoes removed and the BMI [weight $(\mathrm{kg}) /$ height $\left.\left(\mathrm{m}^{2}\right)\right]$ was calculated. Waist circumference was measured using a soft tape on standing subjects midway between the lowest rib and the iliac crest. Hip circumference was measured over the widest part of the gluteal region and the waist-to-hip ratio was calculated accordingly.

Type II diabetes and IGT were defined as follows: Type II diabetes by either 1 . or 2 . or both: 1 . diagnosis of diabetes at the age of 40 years or older and current treatment with antidiabetic agents or diet 2. meeting the WHO criteria [16], a fasting venous plasma glucose concentration equal or greater than $7.8 \mathrm{mmol} / \mathrm{l}$ and/or $2 \mathrm{~h}$ post OGTT venous plasma glucose concentration equal or greater than $11.1 \mathrm{mmol} / \mathrm{l}$. IGT: 1 . fasting venous plasma glucose concentrations less than $7.8 \mathrm{mmol} / \mathrm{l}$ and 2. 2-h OGTT venous plasma glucose concentrations between $7.8 \mathrm{mmol} / \mathrm{l}$ and $11.1 \mathrm{mmol} / \mathrm{l}$. Subjects with either Type II diabetes or IGT were considered to have abnormal glucose tolerance. Subjects meeting the criteria for Type II diabetes or IGT respectively were designated as probands. Recently new criteria for Type II diabetes and IGT have been proposed; Type II diabetes: 1 . fasting plasma glucose equal or greater than $7.0 \mathrm{mmol} / \mathrm{l}$. IGT: 1 . fasting plasma glucose less than $7.0 \mathrm{mmol} / \mathrm{l}$ and 2. 2-h OGTT venous plasma glucose concentrations between $7.8 \mathrm{mmol} / \mathrm{l}$ and $11.1 \mathrm{mmol} / \mathrm{l}$. Subjects meeting the new proposed criteria were designated as probands in seperate calculations.

Statistical analysis. Chi-square tests of proportions were used to compare responding twin pairs that were not examined $(n=672)$ and those that were examined $(n=303)$ with respect to zygosity, sex and prevalence of Type II diabetes based on questionnaire information. The prevalence of Type II diabetes and IGT among MZ and DZ twins after the OGTT, according to the criteria outlined above, were likewise tested with chisquare tests.

Concordance rates. Pairwise concordances, i.e. the proportion of concordant twin pairs among all affected pairs, and $95 \%$ confidence intervals were estimated for $\mathrm{MZ}$ and $\mathrm{DZ}$ twin pairs and compared with a chi-square test [17]. Probandwise concor- 
Table 1. Concordance rates and prevalence for Type II diabetes and abnormal glucose tolerance (Type II diabetes + IGT) in 303 clinically investigated twin pairs. (95\% confi-

\begin{tabular}{|c|c|c|c|c|c|c|}
\hline Subjects & No. pairs & $\begin{array}{l}\text { No. pairs } \\
\text { concordant }\end{array}$ & $\begin{array}{l}\text { No. pairs } \\
\text { discordant }\end{array}$ & $\begin{array}{l}\text { Probandwise } \\
\text { concordance }\end{array}$ & $\begin{array}{l}\text { Pairwise } \\
\text { concordance }\end{array}$ & $\begin{array}{l}\text { Prevalence } \\
(\%)\end{array}$ \\
\hline \multicolumn{7}{|c|}{ Type II diabetes } \\
\hline \multirow[t]{2}{*}{ Monozygotic } & 125 & 9 & 18 & $0.50(0.32-0.71)$ & $0.33(0.17-0.54)$ & $14.4(10.0-18.8)$ \\
\hline & & 5 & 17 & $0.37(0.19-0.55)$ & $0.23(0.05-0.41)$ & $10.8(7.0-14.6)$ \\
\hline \multirow[t]{2}{*}{ Dizygotic } & 178 & 8 & 27 & $0.37(0.21-0.55)$ & $0.23(0.10-0.40)$ & $12.1(8.7-15.5)$ \\
\hline & & 4 & 36 & $0.18(0.07-0.29)$ & $0.10(0.01-0.19)$ & $12.4(9.0-15.8)$ \\
\hline \multicolumn{7}{|c|}{ Abnormal glucose tolerance } \\
\hline \multirow[t]{2}{*}{ Monozygotic } & 125 & 26 & 31 & $0.63(0.49-0.75)^{\mathrm{b}}$ & $0.46(0.32-0.59)^{\mathrm{a}}$ & $33.2(27.4-39.0)$ \\
\hline & & 21 & 33 & $0.56(0.45-0.67)$ & $0.39(0.26-0.52)^{\mathrm{a}}$ & $30.0(24.0-35.7)$ \\
\hline \multirow{2}{*}{ Dizygotic } & 178 & 27 & 71 & $0.43(0.33-0.53)$ & $0.28(0.20-0.39)$ & $35.3(30.3-40.3)$ \\
\hline & & 21 & 76 & $0.36(0.27-0.45)$ & $0.22(13.8-0.30)$ & $33.1(28.2-38.0)$ \\
\hline
\end{tabular}

dance rates, i.e. the proportion of affected co-twins among cotwins of independently ascertained probands [18, 19], and $95 \%$ confidence intervals were estimated for MZ and DZ twin pairs. This estimates the risk of disease among co-twins of affected twins and is comparable with estimates of recurrence risk in other groups of relatives and in the general population.

Interclass correlations. Monozygotic twins have identical genotypes and any differences are theoretically due to environmental factors. Dizygotic twins, however, share on average $50 \%$ of their genes. The extent to which MZ twins are more alike than DZ twins are therefore presumed to reflect a genetic influence on the phenotype in question. Heritability $\left(h^{2}\right)$ expresses the proportion of the total variation of a trait attributable to genetic variation and can be estimated by comparing the similarity of a given phenotype within monozygotic twin pairs with the similarity within dizygotic twin pairs. Interclass correlations is a method to measure resemblance within twin pairs $[r=\operatorname{cov}$ $($ twin 1 , twin 2) $/ \sqrt{ }$ var (twin 1) $\times \operatorname{var}(\operatorname{twin} 2)]$ [20]. Statistical comparisons of interclass correlations were made after transformation using the Fisher z-transformation. All tests applied were two-tailed and $p<0.05$ was considered significant. The heritability is expressed as twice the difference of the interclass correlation of $\mathrm{MZ}$ and DZ twins $\left(\mathrm{h}^{2}=2\left(r_{\mathrm{MZ}}-r_{\mathrm{DZ}}\right)\right)$ [21].

Model-fitting analyses. The total phenotypic variance is the sum of the variance attributable to effects of both genotype and environmental factors. Aetiological models tested included the following contributions to variance; genetic variance due to additive genetic effects $\left(\mathrm{V}_{\mathrm{A}}\right)$ or dominance $\left(\mathrm{V}_{\mathrm{D}}\right)$ and environmental variance due to an individual environment not shared with co-twin $\left(\mathrm{V}_{\mathrm{E}}\right)$ or a common environment shared among co-twins $\left(\mathrm{V}_{\mathrm{C}}\right)$. We used $\mathrm{MX}$ software package [21], a programme for linear structural equation modelling, to estimate the variance components and to compare the different models. The fit of each model was assessed by maximum-likelihood methods and resulted in a chi-square goodness of fit index and probability value which tested the agreement between the observed and the predicted statistics. A small goodness of fit chi-squared value, a high $p$-value and a low AIC (Akaike's Information Criterion), which equals the chi-squared value minus two times the degree of freedom, indicates good correspondence and was used in comparisons of each model leading to a best fitting model.

Before calculating interclass correlations and testing aetiological models the data for BMI, waist-to-hip ratio, plasma glucose and insulin concentrations were subjected to logarithmic transformations to reduce skewness. The transformations yielded approximately normal distributions.

\section{Results}

Examined versus not examined responding subjects. The prevalence of self-reported Type II diabetes was $4.6 \%$ in the 975 twin pairs who responded to the mailed questionnaire. Among the 303 responding pairs who were subsequently clinically examined the prevalence of self-reported Type II diabetes was $5.9 \%$ compared with $3.9 \%$ in the not examined responding pairs $(n=672$ pairs). This difference was not statistically significant (examined vs not examined, $3.9 \%$ vs $5.9 \%, p=0.07)$. Both the examined pairs and the not examined pairs had similar ages (67.0 vs 67.5 years). Examined subjects, however, were more likely to be male (examined vs not examined, 48.8 vs $39.0 \%, p<0.01)$. The distribution of the sexes in the examined cohort was similar to what is found in the general population. The examined cohort contained more MZ twins compared with the not examined group (41.3 vs $58.7 \%, p<0.001)$. This distinction is difficult to make given that $14.6 \%$ of the twins who were not examined had unknown zygosity, i.e. not fulfilling the criteria for either $M Z$ or DZ based on the questionnaire. There was no great difference in self-reported pairwise concordance rates for $\mathrm{MZ}$ and $\mathrm{DZ}$ twin pairs respectively between the group of responding not examined twin pairs $(n=672$ pairs; MZ, $0.18 ; \mathrm{DZ}, 0.11)$ and the group of examined twin pairs $(n=303$ pairs; MZ, 0.25; DZ, $0.00)$.

Clinical examination (Table 1). We found that 79 clinically examined subjects had Type II diabetes. The prevalence of Type II diabetes was accordingly $13.0 \%$ [MZ $(n=36), 14.4 \%$; DZ $(n=43), 12.1 \%$, $p=0.5$, Table 1]. The prevalence was slightly, though not significantly, higher among male twins $(14.6 \%)$ compared with female twins $(11.6 \%), p=0.3$. More than half $(n=4354 \%)$ were diagnosed as a result of the OGTT (16 had fasting glucose $\geq 7.8 \mathrm{mmol} / \mathrm{l}$ and 27 had 2 -h glucose $\geq 11.1 \mathrm{mmol} / \mathrm{l}$ ). The mean duration of diabetes in the remaining Type II diabetic sub- 
Table 2. Interclass correlations and heritability estimates for continuous anthropometric and metabolic variables in monozygotic $(n=125)$ and dizygotic $(n=178)$ twin pairs

\begin{tabular}{lllll}
\hline Phenotype & Interclass correlation & $P$ value & Heritability \\
\cline { 2 - 5 } & $\mathrm{MZ}$ & $\mathrm{DZ}$ & $<\left(\mathrm{r}_{\mathrm{MZ}} \mathrm{r}_{\mathrm{DZ}}\right)$ \\
\hline Weight & 0.78 & 0.39 & $<0.001$ & 0.78 \\
Body mass index & 0.68 & 0.28 & $<0.001$ & 0.80 \\
Waist/hip ratio & 0.75 & 0.72 & 0.66 & 0.06 \\
Fasting plasma glucose & 0.36 & 0.23 & 0.34 & 0.26 \\
120 min OGTT plasma glucose & 0.52 & 0.26 & 0.05 & 0.52 \\
Fasting plasma insulin & 0.51 & 0.38 & $<0.06$ & 0.26 \\
30 min OGTT plasma insulin & 0.48 & 0.23 & & 0.50 \\
\hline
\end{tabular}

Table 3. Best fitting models to Type II diabetes and abnormal glucose tolerance (IGT + Type II diabetes) estimated by means of structural equation modelling (95\% confidence interval) in 303 twin pairs

\begin{tabular}{|c|c|c|c|c|c|c|c|}
\hline \multirow[t]{2}{*}{ Phenotype } & \multirow[t]{2}{*}{ Model } & \multicolumn{3}{|c|}{ Components of variance } & \multicolumn{3}{|c|}{ Goodness of fit tests } \\
\hline & & $\begin{array}{l}\text { Additive genetic } \\
\mathrm{V}_{\mathrm{A}}\end{array}$ & $\begin{array}{l}\text { Shared } \\
\text { environment } \\
\mathrm{V}_{\mathrm{C}} \\
\end{array}$ & $\begin{array}{l}\text { Non-shared } \\
\text { environment } \\
V_{\mathrm{E}} \\
\end{array}$ & $\overline{\text { chi }^{2}}$ & $p$-value & AIC \\
\hline Type II diabetes & $\begin{array}{l}\text { ACE } \\
\mathrm{CE} \\
\mathrm{AE}\end{array}$ & $\begin{array}{l}\mathbf{0 . 2 6}(\mathbf{0 . 0}-\mathbf{0 . 8 5}) \\
- \\
0.72(0.48-0.88)\end{array}$ & $\begin{array}{l}\mathbf{0 . 4 1}(\mathbf{0 . 0}-\mathbf{0 . 7 5}) \\
0.60(0.40-0.76) \\
-\end{array}$ & $\begin{array}{l}\mathbf{0 . 3 3}(\mathbf{( 0 . 2 4}-\mathbf{0 . 6 0 )} \\
0.40(0.24-0.60) \\
0.28(0.12-0.52)\end{array}$ & $\begin{array}{l}\mathbf{0 . 5 5} \\
1.04 \\
2.16\end{array}$ & $\begin{array}{l}\mathbf{0 . 9 1} \\
0.91 \\
0.71\end{array}$ & $\begin{array}{l}\mathbf{- 5 . 4 5} \\
-6.96 \\
-5.84\end{array}$ \\
\hline $\begin{array}{l}\text { IGT + Type II } \\
\text { diabetes }\end{array}$ & $\begin{array}{l}\mathbf{A E} \\
\mathrm{ACE} \\
\mathrm{CE}\end{array}$ & $\begin{array}{l}\mathbf{0 . 6 1}(\mathbf{0 . 3 9 - 0 . 7 8 )} \\
0.61(0.19-0.78) \\
-\end{array}$ & $\begin{array}{l}\overline{0} \\
0.00(0.00-0.30) \\
0.40(0.23-0.55)\end{array}$ & $\begin{array}{l}\mathbf{0 . 3 9}(\mathbf{0 . 2 2}-\mathbf{0 . 6 1}) \\
0.39(0.22-0.61) \\
0.60(0.45-0.77)\end{array}$ & $\begin{array}{l}\mathbf{1 . 1 7} \\
1.17 \\
7.84\end{array}$ & $\begin{array}{l}\mathbf{0 . 8 8} \\
0.76 \\
0.10\end{array}$ & $\begin{array}{l}-\mathbf{6 . 8 3} \\
-4.83 \\
-0.16\end{array}$ \\
\hline
\end{tabular}

jects with known Type II diabetes $(n=36)$ was at the time of examination 6 (range 1-14) years for the MZ and 8 (range 1-19) years for the DZ Type II diabetic twins. We found that 129 subjects $(21.4 \%)$ had impaired glucose tolerance leading to a total of 208 twins $(34.4 \%)$ with abnormal glucose tolerance (IGT or Type II diabetes). The prevalence was not related to sex (men: $35.4 \%$, women: $33.5 \%$ ) or zygosity [MZ $(n=85), 33.2 \%$; DZ $(n=123), 35.3 \%$ ].

Concordance (Table 1). The concordance among MZ and $\mathrm{DZ}$ pairs for known diabetes alone (MZ, 0.25; DZ, 0.00) were not very different. After including the 16 twins diagnosed with Type II diabetes as a result of high fasting glucose values the concordance rates were similar (MZ, 0.26; DZ, 0.14). In all 62 pairs were identified in which one or both twins had Type II diabetes. The probandwise and pairwise concordances are listed in Table 1. The concordance for Type II diabetes among MZ and DZ pairs was not very different, although it tended to be higher for MZ twins. In 155 of 303 pairs one or both twins had an abnormal glucose tolerance. The probandwise concordances were $0.63(0.49-0.75)$ for MZ twin pairs and $0.43(0.33-0.53)$ for DZ pairs $(p<0.01)$. The pairwise concordance rates $[0.46(0.32-0.59)$ and 0.28 (0.20-0.39) for $\mathrm{MZ}$ and $\mathrm{DZ}$ pairs respectively] were likewise significantly different, $(p<0.05)$. Almost similar concordance rates were obtained using the new proposed criteria for Type II diabetes and IGT (Table 1).
Interclass correlations (Table 2). All examined twin pairs (MZ, 125 pairs; DZ, 178 pairs) were included in the calculation of interclass correlations. The interclass correlations for absolute weight were $r=0.78$ for $\mathrm{MZ}$ and $r=0.39$ for DZ. The interclass correlations for BMI were $r=0.68$ for $\mathrm{MZ}$ and $r=0.28$ for DZ. The differences in interclass correlations for weight and BMI between the two zygosities were highly significant $(p<0.001)$. The heritability estimates were consequently high indicating a major genetic contribution to variation of weight and BMI. The heritability of waist-to-hip ratio, $\mathrm{h}^{2}=0.06$, was low. No significant differences in interclass correlations were found for fasting plasma glucose and insulin, Table 2, indicating a relatively small genetic contribution to variation of these metabolic variables. The interclass correlations for $120 \mathrm{~min}$ OGTT plasma glucose differed much between $\mathrm{MZ}$ and DZ indicating a genetic component in the variation of the variable. Furthermore, the heritability for $30 \mathrm{~min}$ OGTT plasma insulin was relatively high $\left(\mathrm{h}^{2}=0.50\right)$ nearly reaching the level of significance $(p<0.06)$.

Modelling analyses (Table 3, 4). For Type II diabetes the data did not permit distinguishing between the $\mathrm{ACE}, \mathrm{AE}$ and $\mathrm{CE}$ models (A, additive genetic variance; $\mathrm{C}$, shared environmental variance; $\mathrm{E}$, nonshared environmental variance). The heritability, i.e. proportion of variance attributable to additive genetic effects, was $26 \%$ in the ACE model, $72 \%$ in the AE model and non-existing in the CE model, Table 3. 
Table 4. Best fitting models to metabolic and anthropometric variables associated with glucose intolerance estimated by means of structural equation modelling in 303 twin pairs

\begin{tabular}{|c|c|c|c|c|c|c|c|}
\hline \multirow[t]{2}{*}{ Phenotype } & \multirow[t]{2}{*}{ Model } & \multicolumn{3}{|c|}{ Components of variance } & \multicolumn{3}{|c|}{ Goodness of fit tests } \\
\hline & & $\begin{array}{l}\text { Additive } \\
\text { genetic } \\
\mathrm{V}_{\mathrm{A}} \\
\end{array}$ & $\begin{array}{l}\text { Shared } \\
\text { environment } \\
\mathrm{V}_{\mathrm{C}} \\
\end{array}$ & $\begin{array}{l}\text { Non-shared } \\
\text { environment } \\
\mathrm{V}_{\mathrm{E}} \\
\end{array}$ & $\mathrm{chi}^{2}$ & $p$-value & AIC \\
\hline Fasting plasma glucose & $\mathrm{AE}$ & 0.38 & - & 0.62 & 9.50 & 0.05 & 1.50 \\
\hline 120 min OGTT plasma glucose & $\mathrm{AE}$ & 0.51 & - & 0.49 & 1.66 & 0.80 & -6.34 \\
\hline Fasting plasma insulin & $\mathrm{ACE}$ & 0.19 & 0.30 & 0.51 & 3.13 & 0.37 & -2.87 \\
\hline 30 min OGTT plasma insulin & $\mathrm{AE}$ & 0.47 & - & 0.53 & 3.38 & 0.50 & -4.62 \\
\hline Weight & $\mathrm{AE}$ & 0.76 & - & 0.24 & 1.10 & 0.90 & -6.90 \\
\hline Body mass index & $\mathrm{AE}$ & 0.65 & - & 0.35 & 2.68 & 0.61 & -5.32 \\
\hline Waist/hip ratio & ACE & 0.20 & 0.59 & 0.22 & 6.03 & 0.11 & 0.03 \\
\hline
\end{tabular}

For abnormal glucose tolerance there was consistency between the two best fitting models with an additive genetic component of variance of $61 \%$ in both models. The CE model with no genetic effect fitted significantly worse. Table 4 shows the best fitting models for the metabolic and anthropometric variables associated with glucose intolerance. The best fitting model for fasting plasma glucose, $120 \mathrm{~min}$ OGTT plasma glucose and 30 min OGTT plasma insulin was an AE model. For fasting insulin the best fitting model included a shared environmental component as well (ACE model). The proportion of variance attributable to additive genetic effects was $38 \%$ for fasting plasma glucose, $51 \%$ for $120 \mathrm{~min}$ OGTT plasma glucose, $19 \%$ for fasting plasma insulin and $47 \%$ for $30 \mathrm{~min}$ OGTT plasma insulin. The best fitting models for the anthropometric variables were likewise AE models, with a heritability estimate of $76 \%$ for absolute weight, $65 \%$ for BMI and $20 \%$ for waist-to-hip ratio.

\section{Discussion}

The similar concordance estimates for Type II diabetes per se among MZ and DZ twins in this study may appear somewhat contradictory compared with previous twin studies [2-9]. On the other hand, the concordance rate (i.e. the risk of Type II diabetes among healthy co-twins to diabetic twins) of 0.50 in MZ twins is, in fact, in accordance with the results from several previous studies [6-8]. Thus, the reason for the lack of an important difference in concordance rates between $\mathrm{MZ}$ and $\mathrm{DZ}$ twins in our study is a high concordance rate of 0.37 among DZ twin pairs. Specifically, the concordance rate for Type II diabetes in DZ twins seems to be higher than the age-equivalent risk of approximately $22 \%$ [22] for first degree relatives (i.e. siblings) who have the same number of genes in common with their Type II diabetic or non-Type II diabetic probands compared with the DZ twins. The results propose that twin status per se, or perhaps that shared environment (as for example the intrauterine environment $[23,24]$ ) may be important in the aetiology of non-insulin dependent diabetes mellitus.

Concordance for disease might be due to both genetic and shared environmental factors. The structural equation modelling analyses show aetiologically fitting models which distinguish between the contribution from additive genetic and shared environmental to variance of a given phenotype. The data for Type II diabetes did not permit statistical distinction between the three best fitting models. The heritability estimates obtained from the models ranged from $0-72 \%$, indicating a large uncertainty in this method or merely reflecting the heterogeneity of the disease. When, however, comparing with the concordance rates for Type II diabetes per se, which are based on the same data, we are inclined to believe that the ACE model with a heritability of $26 \%$ (in bold, Table 3 ) is the best fitting model. The best fitting models for abnormal glucose tolerance were an $\mathrm{AE}$ and $\mathrm{ACE}$ model. The proportion of variance attributable to additive genetic effects was the same in both models $(61 \%)$, which is consistent with the concordance rates for abnormal glucose tolerance, supporting the notion of a major genetic influence on the development of abnormal glucose tolerance.

Because of the arbitrary definitions of impaired glucose tolerance and Type II diabetes we estimated heritability of the continuous metabolic variables reflecting glucose intolerance (i.e. fasting plasma glucose and 120 min OGTT plasma glucose) by means of interclass correlations and aetiological models. The heritability estimate for fasting plasma glucose by means of interclass correlations was $26 \%$ (38\% by means of aetiological modelling) with no difference in correlation between MZ and DZ pairs. Both methods estimated a higher heritability for $120 \mathrm{~min}$ plasma glucose (52 and $51 \%$, respectively) than for fasting plasma glucose. Furthermore we found a statistically significant difference in correlation for 120 min plasma glucose between MZ and DZ twins confirming the genetic component in abnormal glucose tolerance. 
The two most important pathophysiological components leading to IGT and Type II diabetes are considered to be peripheral insulin resistance and inappropriate insulin secretion [1]. Therefore, we investigated to which extent the variance of these variables (i.e. indirectly estimated by fasting plasma insulin and $30 \mathrm{~min}$ OGTT plasma insulin concentrations, respectively) could be explained by genetic components. The heritability, by means of interclass correlations, for fasting plasma insulin was non-significant. For 30 min plasma insulin, however, the difference in correlation between the two zygosities approached a level of significance $(p<0.06)$. The heritability estimates, by means of model analyses, reflected this finding. The results confirm the importance of environmental factors determining both glucose intolerance per se, and the major pathophysiological components leading to this state, but suggest a genetic aetiological component for 120 min OGTT plasma glucose and $30 \mathrm{~min}$ plasma insulin reflecting glucose intolerance and insulin secretion, respectively [25, 26].

Obesity, and in particular abdominal obesity, is a known risk factor for the development of abnormal glucose tolerance and Type II diabetes. The heritability estimates for absolute weight and BMI indicated a major genetic component in the development of obesity. The heritability for the distribution of obesity (i.e. waist/hip ratio), however, was lower, indicating a major influence of environmental factors. The high heritability for BMI and absolute weight and the somewhat lower heritability for waist-to-hip ratio is in accordance with previous studies [27-29].

The examined twin sample in this study has a potential risk of selection bias due to the incomplete questionnaire respondence rate and incomplete participation in the following clinical examination. This is a major problem in epidemiological studies particularly if the examined sample differs in disease prevalence compared with the total population. In this study the relatively small sample of responding examined twins ( $19.7 \%$ of total twin population) had a tendency towards a higher self-reported Type II diabetes prevalence than pairs that were not-examined. A higher disease prevalence could lead to overestimated concordance rates. In this study, however, we found concordance rates which were lower than previously reported [2-9]. The difference in the distribution of zygosity and sex between the group of not examined and examined responding pairs, with an overrepresentation of MZ twin pairs and men, would only influence the results if the prevalence of Type II diabetes among men or MZ twins were considerably higher than among women and DZ twins, respectively. We did not find this to be the case. Therefore, we do not believe the different zygosity or distribution of the sexes or both to have a major impact on the results.

There was no distinctive difference between the responding group of twins that were not examined and the group of clinically examined twins when comparing the concordance rates based on information obtained from the questionnaires only. Thus, these selfreported concordance rates for Type II diabetes show a similar tendency compared with the absolute concordance rates after the OGTT (i.e. a non-significant difference between MZ and DZ pairs). The absolute concordance rates based on the OGTT, however, were substantially higher than those based on the questionnaire only. This emphasises the importance of carrying out an OGTT in non-diabetic subjects. Furthermore it shows that precautions should be taken when interpreting results from studies not including diagnostic testing in the identification of the diabetic subjects.

Our study is an observational study in which all eligible twins have been examined. Although a considerable number of twins were studied, the number of affected pairs was relatively small. The statistical power of the comparison of the concordance rates for Type II diabetes might therefore not have been optimal. Consequently, we cannot exclude that the slightly higher concordance rate for Type II diabetes among MZ twin pairs could have reached the level of significance if we had included more twins. On the other hand, the higher concordance for the criteria of abnormal glucose tolerance in MZ, compared with DZ, twins reached statistical significance supporting a genetic influence on glucose intolerance.

Our study confirms the notion of a multifactorial aetiology of Type II diabetes including both genetic and non-genetic factors. It strongly supports the contribution of a non-genetic component to the aetiology of Type II diabetes per se, but the study also indicates that genes have a roll in the aetiology of early abnormal glucose tolerance including impaired glucose tolerance (IGT). We therefore propose that genetic predisposition might be important for the development of abnormal glucose tolerance, and that non-genetic factors possibly have a predominant role in controlling whether a genetically predisposed subject progresses to overt Type II diabetes.

Acknowledgements. The authors would like to acknowledge the expert technical assistance of Mrs. L. Hansen, Mrs. H. Hansen, Mrs. C. B. Olsen and Mrs. K. Dyregaard. Dr. A. Green is acknowledged for statistical advice and commenting on the manuscript. Dr. N.Holm from the Danish Twin Registry is acknowledged. The study was supported by grants from the NOVO Foundation, Danish Medical Research Fund, Sygekassernes Helsefond and The Danish Diabetes Association.

\section{References}

1. Beck-Nielsen H, Groop L (1994) Metabolic and genetic characterization of prediabetic states. Sequence of events leading to non-insulin-dependent diabetes mellitus. J Clin Invest 94: 1714-1721

2. Then Bergh H (1939) Zur Frage der psychischen und neurologischen Erscheinungen bei Diabeteskranken und de- 
ren Verwandten. Zeitschrift für die Gesamte Neurologie und Psychiatrie 165: 278-283

3. Harvald B, Hauge M (1965) Hereditary factors elucidated by twin studies. In: Neel JV, Shaw MW, Schull WJ (eds) Genetics and the epidemiology of chronic diseases. Department of Health, Education and Welfare, Washington, DC, pp 61-76

4. Gottlieb MS, Root HF (1968) Diabetes Mellitus in twins. Diabetes 17: 693-704

5. Tattersall RB, Pyke DA (1972) Diabetes in identical twins. Lancet 2 (787): 1120-1125

6. Barnett AH, Eff C, Leslie RD, Pyke DA (1981) Diabetes in identical twins. A study of 200 pairs. Diabetologia 20: 87-93

7. Newman B, Selby JV, King MC, Slemenda C, Fabsitz R, Friedman GD (1987) Concordance for Type 2 (non-insulin-dependent) diabetes mellitus in male twins. Diabetologia 30: 763-768

8. Committee on diabetic twins, Japan Diabetes Society (1988) Diabetes Mellitus in twins: a cooperative study in Japan. Diabetes Res Clin Pract 5: 271-280

9. Kaprio J, Tuomilehto J, Koskenvuo M et al. (1992) Concordance for Type I (insulin-dependent) and Type 2 (non-insulin-dependent) diabetes mellitus in a population-based cohort of twins in Finland. Diabetologia 35: 1060-1067

10. Gedda L (1966) The use of twins in epidemiological studies. Report of the WHO meeting of investigators on methodology of twin studies. Acta Genet Med Gemellol 15: 109-128

11. Hauge M (1981) The Danish Twin Register. In: Mednick SA, Baert AE, Bachmann BP (eds) Prospective longitudinal research. An empirical basis for the primary prevention of psychosocial disorders. Oxford University Press, Oxford, UK, pp 217-221

12. Kyvik KO, Green A, Beck-Nielsen H (1995) The new Danish Twin Register: Establishment and analysis of twinning rates. Int J Epidemiol 24: 589-596

13. Magnus P, Berg K, Nance WE (1983) Predicting zygosity in Norwegian twin pairs born 1915-1960. Clin Genet 24: 103-112

14. Kyvik KO, Green A, Beck-Nielsen H (1995) Concordance rates of insulin dependent diabetes mellitus: a populationbased study of young Danish twins. BMJ 311: 913-917

15. Hemmilä I, Dakubu S, Mukkala V-M, Siitari H, Lövgren T (1984) Europium as a label in time-resolved immunofluorometric assays. Analytical Biochemistry 137: 335-343

16. Keen H (1992) Diabetes diagnosis. In: Alberti KGMM, Defronzo RA, Keen H, Zimmet P (eds) International Text- book of Diabetes Mellitus. John Wiley \& son, Chichester, New York, Brisbane, Toronto, pp 19-30

17. Allen G, Harvald B, Shields J (1967) Measures of twin concordance. Acta Genetica et Statistica Medica 17: 475-481

18. McGue M (1992) When assessing twin concordance, use the probandwise not the pairwise rate. Schizophr Bull 18: 171-176

19. Smith C (1974) Concordance in twins: methods and interpretation. Am J Hum Genet 26: 454-466

20. Neale MC, Cardon LR (1992) Data summary. In: Methodology for genetic studies of twins and families. Kluwer Academic Publishers, Dordrecht, Boston, London. NATO ASI series, pp 35-53

21. Neale MC (1994) Mx: Statistical modeling. Computer programme, Box $710 \mathrm{MCV}$, Department of Psychiatry, Richmond, Va

22. Köbberling J, Tillil H (1982) Empirical risk figures for first degree relatives of non-insulin dependent diabetics. In: Kobberling J, Tattersall R (eds) The genetics of diabetes mellitus. Academic Press, London and New York, pp 201-209

23. Hales CN, Barker DJP, Clark PMS et al. (1991) Fetal and infant growth and impaired glucose tolerance at age 64 . BMJ 303: 1019-1022

24. Poulsen P, Vaag A, Kyvik KO, Møller-Jensen D, BeckNielsen H (1997) Low birth weight is associated with noninsulin-dependent diabetes mellitus in discordant monozygotic and dizygotic twin pairs. Diabetologia 40: 439-446

25. Mayer EJ, Newman B, Austin MA (1996) Genetic and environmental influences on insulin levels and the insulin resistance syndrome: an analysis of woman twins. Am J Epidemiol 143: 323-332

26. Vaag A, Henriksen JE, Madsbad S, Holm N, Beck-Nielsen $H$ (1995) Insulin secretion, insulin action and hepatic glucose production in identical twins discordant for NIDDM. J Clin Invest 95: 690-698

27. Bouchard C, Tremblay A, Després J-P et al. (1990) The response to long-term overfeeding in identical twins. N Engl J Med 322: 1477-1482

28. Selby JV, Newman B, Quesenberry CP (1990) Genetic and behavioral influences on body fat distribution. Int J Obesity 14: 593-602

29. Cardon LR, Carmelli D, Fabsitz RR, Reed T (1994) Genetic and environmental correlations between obesity and body fat distribution in adult male twins. Hum Biol 3: 465-479 